\title{
Conceptions of nursing staff about psychiatric care in general hospital
}

\author{
Concepções da equipe de enfermagem sobre assistência psiquiátrica em hospital geral
}

Leila Mariza Hildebrandt' ${ }^{1}$ João Fernando Marcolan²

Objective: to understand the concepts of Nursing professionals about the hospitalization of people with mental disorders admitted to psychiatric units of general hospitals. Methods: this is a qualitative research developed in three general hospitals. The data collection was carried out through semi-structured interviews and systematic observation. Thirty Nursing professionals were interviewed. The data analysis was based on content analysis. Results: issues concerning fragility were identified in the training of Nursing professionals, prejudices related to psychiatric care in general hospitals and presence of lunatic characteristics in the surveyed institutions. Conclusion: investments are needed in the training of nursing professionals to qualify the assistance and social interventions to minimize the prejudice against people with mental disorder.

Descriptors: Nursing; Mental Health; Hospitals, General; Mental Health Assistance.

Objetivo: compreender as concepções de profissionais de Enfermagem acerca da internação de pessoas com transtorno mental internadas em unidades psiquiátricas de hospitais gerais. Métodos: pesquisa qualitativa, desenvolvida em três hospitais gerais. A coleta de dados se deu por meio de entrevista semiestruturada e observação sistemática. Foram entrevistados 30 profissionais de Enfermagem. A análise dos dados baseouse na análise de conteúdo. Resultados: identificam-se questões relativas à fragilidade na formação dos profissionais de Enfermagem, preconceitos em relação à assistência psiquiátrica em hospital geral e presença de características manicomiais nas instituições pesquisadas. Conclusão: são necessários investimentos na formação de profissionais de enfermagem para qualificar a assistência prestada e intervenções sociais para minimizar o preconceito em relação à pessoa com transtorno mental.

Descritores: Enfermagem; Saúde Mental; Hospitais Gerais; Assistência à Saúde Mental.

${ }^{1}$ Universidade Federal de Santa Maria. Palmeira das Missões, RS, Brazil.

${ }^{2}$ Universidade Federal de São Paulo. São Paulo, SP, Brazil.

Corresponding author: Leila Mariza Hildebrandt

Rua dos Carajás 82, Pindorama, CEP: 98700-000, Ijui, RS, Brazil. E-mail: leilahildebrandt@yahoo.com.br 


\section{Introduction}

The Movement of the Brazilian Psychiatric Reform, among its assumptions, provides attention to patients with mental disorders in their place of conviviality, from the development and implementation of services that offer psychosocial support to including them in the dynamics of daily life $^{(1)}$. It should be noted that the Brazilian Psychiatric Reform has its implementation grounded in ministerial laws and ordinances that regulate and guide the actions of the various institutions, to define the form of organization of mental health care $^{(2)}$ to break the classic Psychiatry paradigm. However, practices based in the hospital-centered ideology are still present in the daily routine of health institutions.

One of the intervention spaces in the mental health field, as proposed by the psychiatric reform, is when hospitalization is necessary for the general hospital for the individual with a mental disorder that has to worsen symptoms. With the view directed to these places, it is understood that there is still a prejudiced culture that this individual should be treated in separate space, in a psychiatric hospital, because carry the social stigma of dangerous, unpredictable and incurable. Opposed to this view, psychiatric hospitalization in a general hospital consists of a therapeutic device to overcoming the asylum care, to meet people with acute and severe conditions when exhausted the possibilities of extra-hospital interventions, as Ministerial Ordinance No. 224 and recommendations of the II National Conference on Mental Health ${ }^{(2-3)}$. However, professionals working in general hospitals sometimes do not have enough skills to meet the demands of these people.

Psychiatric hospitalization remains an important therapeutic option, especially for people with severe mental disorders. Increasingly, the general hospitals need to expand the number of integral care beds in mental health and be coordinated with other services that make the care network in this field. Psychiatric beds are constituted in the rear for assistance to people where the component about the mental disorder is relevant.

This study has as its central question: Which is the conception of nursing professionals that assist people with mental disorders admitted to general hospitals for psychiatric hospitalization in this space?

Thus, this research aimed to understand the concepts of nursing professionals about the hospitalization of people with mental disorders admitted to psychiatric units of general hospitals.

\section{Methods}

This is a qualitative research developed in three psychiatric units of general hospitals in three cities in the northern region of Rio Grande do Sul, Brazil, linked to the $15^{\text {th }}$ Regional Health Coordination. It is noteworthy that, in this region, these are the general hospitals that have beds for psychiatric hospitalization. The choice of these places is due to the approach of the public university, the workplace of one of the authors with those hospitals.

The three hospitals relied on a multidisciplinary team, and interventions were based on individual and group care to patients and family, therapeutic workshops, tours and drug interventions. The staff of one of the institutions held meetings in the community to discuss issues related to mental health. One of the hospitals had a specific team to the psychiatric unit, and the other two hospitals had a nursing staff working in rotation scheme between psychiatric units and other units of hospitals.

The subjects that integrated this research were thirty nursing professionals linked to psychiatric units of three chosen general hospitals, of the total of thirty-two professionals. The inclusion criteria of professionals to participate in the study were: working for at least six months in the hospital and assist people with mental disorders. All who met the inclusion criteria were invited to participate and accepted the invitation. The exclusion criteria cited those professionals who, perchance were in health 
license and those who were on vacation at the time of compiling the data. Of the thirty respondents, nineteen were nursing technicians, nine nurses, and two nursing assistants. Of the total participants, twentythree were women and seven men, aged between 20 to 59 years old. Most were married (16), followed by singles (9), divorced (3) and stable (2). The Catholic religion prevailed among the participants, professed by 27 of them.

It is worth noting that some participants had expertise but in other areas such as Audit, Administrative Actions, Education and Health, Public Health Management and Prehospital Care. The only participant who had expertise in the Mental Health area did it in Chemical Dependency and were still attending at the time of the interview. Some participants of the study underwent training offered by the Health Coordination or other health institutions that have organized such events.

To ensure the privacy and confidentiality of the identification of survey participants, the letter 'I' was used for being the first letter of the word Interviewed, followed by the interview number. Data were collected from August 2012 to April 2013, the three shifts of participants (morning, afternoon and evening).

In this research, data collection occurred through the interview with guiding questions, buoyed by the objective of the study. The questions that guided the interviews were: Tell me how you care for the person affected by mental disorders hospitalized in the general hospital? What do you think about the hospitalization of people with mental disorders in general hospitals? How do you see the work developed by staff in individual assistance with mental illness admitted to the hospital? From them, the participants were able to discuss the subject freely, spontaneously, to enrich the research.

The interviews were scheduled to enable the participation of Nursing professionals who worked on all shifts (morning, afternoon and even/odd evening), performed by one of the researchers, in a private room of each hospital, recorded through audio equipment and transcribed. The duration thereof was approximately one hour.

In addition to the interview, the systematic observation was also used as a data collection instrument. From this technique, it was possible to know the reality of the groups because it allowed immersing in three general hospitals, the study locus, and apprehend the individual and collective behaviors of Nursing professionals related to psychiatric hospitalization in a general hospital. The systematic observation was imposed by script, which had questions about the admission of psychiatric patients in the psychiatric inpatient unit, the assistance provided by the Nursing team to that individual in the unit and discharge of psychiatric patients. The observed information was noted in daily. The observation time was approximately 60 hours. The researcher, the author of this article, collected data.

Data analysis was carried out concerning the content analysis and consists of the following stages: pre-analysis, material exploration, and treatment of results and interpretation ${ }^{(4)}$. In the pre-analysis, there was extensive contact with the material collected in the empirical field of the research, its completeness organization, representativeness, homogeneity and relevance to the object under study. At this stage, the registration unit was defined, cuts and categorization forms and coding, in addition to theoretical concepts that guided the analysis. In the second stage, the material exploration, the classification of data, grouped ideas that emerged from the data collection, considered their similarity. The last step involved the interpretation of the data, with the background of the theoretical framework related to the studied topic, remitted the meaning to the context investigated.

The study complied with the formal requirements contained in the national and international standards of regulatory research involving human subjects. 


\section{Results}

Sequentially, the contents analysis of the participant's speeches is found regarding psychiatric hospitalization in a general hospital, whose information were grouped in one category.

\section{The psychiatric hospitalization in a general hospital in the conception of nursing professionals: a view permeated of prejudices and psychiatric practice}

The results of the study, from the analysis of the content of the participants speeches of the survey and information seized in observation, pointed to the presence of prejudice against psychiatry, expressed by society, by patients who accessed the general hospitals locus of the investigation and by the nursing staff: $A t$ first the community was saying those crazy. It was the community's verbiage. And then, there were a lot of people wondering why they put those crazy along the hospital. At first, it was an end of the world to do it in the hospital, placing the crazy together with patients (I 3). This social prejudice is wide, and we can say that it still exists today inside the hospital. The health professionals are not prepared to face this situation yet (I 6).

Thus, every day, it was still possible to see reflections of classical learning of psychiatry in prejudiced and discriminatory attitudes towards people who experience mental illness. These notions, according to one of the interviewees, were reinforced by clinical patients who accessed the general hospitals locus of the research because they are close to the hospitalized subject with mental disorders and reproduce social prejudice: Clinical, some complain a lot. Many complaint about fear of getting in and being attacked, grabbed, fear of theft because is a chemical addiction, is going to steal a watch, a mobile phone to sell it (I 26). Many medical patients still see psychiatry as crazy. It has community resistance. And society, they see as crazy (I 2).

Participants expressed their prejudice and fear of people with mental disorders, strengthening the notion of incurability, unpredictability, aggression, lack of sense of what they do and say. These attitudes were also identified in the observation: I was very scared of patients. Today I know we have to be careful, not turning away because there are very dangerous people, you do not know, like schizophrenics that change from one moment to another (I 11). They make you feel afraid, they never did anything, as have those that you see, angry, but you never try to go alone. It is not easy, if I have to work at night, I'm afraid, it seems that the night everything is quieter. During the day is more bustling, so you feel quieter. Sometimes they say they spend the nights with open eyes, you do not know who the patients are, you have a group of 30, 20 and few, you do not know who they are, of where they come from (I 21).

The respondents also mentioned prejudice and fear of colleagues that developed their actions in other units or the psychiatric unit of the hospital: When we talk with colleagues, 'why they smell bad, why they speak, they do not have a proper language, why they are all the time behind you, how you can do it? I spend one week there, and I think I will be hospitalized.' You must love what you do; it's quite difficult to catch one of the girls on the other side. It is very difficult, even to help. They reject this part (I 4).

In the surveyed institutions there was the division of hospitals between clinical and psychiatric units, "this side and that side." There was resistance from professionals working in clinical units to collaborate in the activities of the psychiatric unit: Even it was not two hospitals, but it was divided. We have the ward of Mental Health in the hospital and the clinic ward. It seems to be two institutions. Even people do not admit that this division exists, that it's just a hospital, but this division exists among employees (I 1). It seems like the Berlin Wall, this side and that side (I 3).

The prejudice against the patient user of psychoactive substances was identified in the content of the speeches of the participants, understanding them as a person without commitment that is limited to the use of drugs, with little prospect of improvement, circumventing rules, being aggressive, manipulator, resistant to treatment and with many relapses: Eating, sleeping, using drugs, eating, sleeping, using drug, stealing, eating, sleeping, using drug and look for (I 3). Crack patients, they have a different feature from the others, they have the street roguery, exchange, theft, everything (I1 3). 
In the surveyed institutions, fragility in the training and qualification of nursing professionals were noted. Some of them have learned to develop their activities in the psychiatric area from the daily tasks, practice, and they did not have prior training to work in the field: Sometimes you do not know how to handle. You make it on your way, and each one acquired a way to deal with them and deal with this way, the way that managed to adapt (I 29). So we go with the experience. All we learned was during the day-to-day, if you work for years, you will learn because you deal with such patients not only here in the clinic, at the emergency also, at the floor because these clinics began to appear nowhere in our area (I 8).

Some participants indicated a lack of discussion about mental health in their respective undergraduate and technical courses and the development of practical activities in mental hospital environment, denote fragility in vocational training in this area of knowledge: Because in their training, in graduation, we do not see everything, they are strokes (I 25). Because in the technical, when we did it, Mental Health is very little (I 29).

However, some professionals attended courses, lectures, and training in other institutions. The hospital did not offer this possibility, did not encourage, and sometimes lacked financial resources to encourage participation in events: Training, we never went. If anyone was going, it was always nurses ahead. I never went to any training; nurses go, seek, then bring to us and pass these things through a meeting. Courses, preparation, these things that we do not have. We always ask what that we would like because we never had, we have no guidance, lack of encouragement from the direction (I 21). When there are courses, usually one of us goes and attends these courses. You cannot say like training, two-day course, lectures, but none of us can work with mental health, and it would be very important. There is no way; we do not have a liberation to go out. Also financially the hospital could not keep paying an employee to take the course (I 4).

\section{Discussion}

This study is limited by the difficulty of generalizing the results depending on the context specificity of each psychiatric unit in a general hospital. Associated with this, an adopted method allows looking at a small universe but in greater depth.

The lack of information and understanding about this subject by the society may increase the stigma of those considered different or crazy, compromises the lives of these individuals, in personal and social level and aggravates their suffering, labeling them as unable to live in the social space ${ }^{(5-6)}$.

These conceptions often pervade the practice of nursing professionals in different health institutions, including the hospitals, as we have seen in our results. It will be important to verify this situation and intervene so that the practice can be changed in the search for respect and citizenship of the subjects and the best quality of care.

The study has implications for the training of nursing professionals regarding mental health, points to the need for educational institutions to strengthen the qualified education for good practices, with guidelines that may be consistent with the assumptions of the current Mental Health Policy in the country. Therefore, nursing should understand the care as a social practice and have internal availability to intervene with the person with a mental disorder, linking up with the team to build therapeutic projects, respecting the specificities of each case ${ }^{(7)}$.

A study of nursing professionals linked to hospital inpatient units showed the lack of planning and organization of activities from the nursing staff, to meet aspects of mental health, fragility in academic training involving this knowledge area and lack of specific physical space to treat patients with mental disorders ${ }^{(8)}$. A similar situation was also identified in nursing professionals who worked in emergency care of a general hospital that reported difficulties in the care of mental patients, for lack of specific knowledge in mental health. They recognized that academic training did not give them enough information to work with these individuals $\mathrm{s}^{(9)}$.

In the case of drug users, a research conducted with nurses at a Chilean general public hospital confirms that the hospitals had fragility in infrastructure and training of human resources, and 
the lack of multidisciplinary work, which produced feelings of powerlessness and fear to deal with this population group, which may have a negative effect on the provided quality of care. Such research underlines the need to train nursing staff to work with the users of alcohol and other drugs, overcome prejudice and thus, improve the care ${ }^{(10)}$.

Daily, it is clear that there is some difficulty in adherence to treatment by the drug users. Commonly, they admit to having problems related to psychoactive substance use and consider the possibility of changes, evaluate their advantages and disadvantages, but often the ambivalence showed evidently. In this sense, therapeutic techniques that can assist in minimizing ambivalence are important and should be considered by health professionals, respecting the subjectivity of each ${ }^{(11)}$. There may also be the notion that the use of these substances will not cause harm or produced losses are not significant in their understanding.

However, it is known that the use of alcohol and other drugs harms in different orders, as shown by a study conducted with 965 adolescents with alcohol consumption and other drugs associated with problems related to school performance as grades below average, not performing school tasks and concentration difficulty ${ }^{(12)}$. It was verified, through observation, in the surveyed institutions that most of them did not seek treatment spontaneously but unwillingly because of pressure from family or compulsorily.

It was noticed, during the research, that nursing professionals lacked specific knowledge of mental health, as the assisted population in general hospital space, required interventions to answer their peculiarities, which occurred in a fragile way. In general, medium level nursing workers who developed their activities in psychiatric units in general hospitals survey participants were from other clinical units and were assigned to that location at their request or by order of their coordinators, performing their duties from general knowledge of nursing and what they considered being the best. These professionals in hospital mental health services usually spend most of the time with patients and are part of the minimum staff of psychiatric units in general hospitals as recommended by the current legislation ${ }^{(2)}$.

Participants recognized that the training received in the courses related to mental health was scarce, which can resonate in the performance of their functions in psychiatric care units. It is necessary to adapt the curricula, both undergraduate and technical level, to the new proposition in the mental health field, to incorporate discussions that include issues relating to the Psychiatric Reform, to the Mental Health Policy, to the construction of care network, to the interdisciplinary team work. However, these changes have been slow when existing and normally have responded to the contexts where courses are included. Thus, the nursing interventions in general hospitals in the assistance context, involving the psychosocial field, require technical and cultural changes to qualifying care for people with mental disorders ${ }^{(9)}$.

Another aspect raised by the participants is related to the lack of qualification activities of the nursing staff in their services, which may compromise the care provided to users with mental disorders and their families and keep the prejudiced views related to these subjects, limiting their act in asylum practices. In line with the identified information, research with mental health services coordinators referred that the training of health professionals is still disarrayed with the propositions of psychiatric reform. Usually, it happens in a fragmented and superficial way, with a little approach to alternative services ${ }^{(13)}$, including psychiatric units in general hospitals.

Nursing professionals should constantly be updated depending on the speed and dynamics with the changes occurring in the health field. Therefore, institutions need to worry to provide discussion spaces for their workers to strengthen them theoretically and enable the exchange of experiences to qualify the provided assistance. In this scenario, it emphasizes the importance of managers to prioritize and enable 
educational activities in mental health, as well as allowing the professionals removal to participate in events involving this area of knowledge ${ }^{(14)}$. The break with traditional psychiatric services does not always indicate changes in behaviors and attitudes of health professionals related to the individual with a mental disorder because the speech that still pervades the daily life of these workers could be linked to the asylum concepts that are crystallized in their practices. In this sense, the substitutive services in the field of Mental Health can be creative and innovative; however, their care technologies still involve segregation, oppression and blaming the other ${ }^{(15)}$.

The participation of professionals in spaces for reflection about the practice allows the interlocution of different knowledge of the actors involved and experiences socialization, which helps to face the daily challenges of health services ${ }^{(9)}$. It is understood that health institutions do not always adopt educational activities as common practice, as observed in hospitals, research locus, which may be related to the fact that they are small cities, far from major urban centers. In this scenario, it emphasizes the importance of the managers definition so that these activities could be prioritized and feasible, to allocate resources for this purpose and allow the professionals removal to participate in events involving the area of mental health $^{(14)}$.

\section{Conclusion}

In this study, we identified that nursing professionals have conceptions that indicate the presence of prejudice related to patients with mental disorders, as evidenced by the observation, made by the respondents, of the users in general hospitals (clinical and psychiatric) and workers who worked in these spaces. This fact came to compromise the provided assistance.

More specifically, the prejudice against the individual user of drugs, especially illegal, was evident in the content of the manifestations of the participants, to devalue it as a citizen person and to understand as someone who does not want to work, without commitments, aggressive, without positive responses to treatment and which has many relapses. These findings were directly related to the lack of knowledge about mental health care and life dynamics of illicit drug users, to strengthen the social stigma that suffers such individuals related to marginality and manipulative behavior with resistance to treatment adherence.

It was clear the lack of training and qualification of nursing professionals to work in the provision of psychiatric care and the lack of initiative of the institutions to resolve the situation. The prejudice of the participants related to the individual with mental illness and the user of alcohol and other drugs, present in daily life, can be minimized with qualified training and continuing education.

\section{Collaborations}

Hildebrandt LM contributed to the conception and project, data collection, analysis and writing of the article. Marcolan JF contributed to the relevant critical review of the intellectual content and final approval of the version to be published.

\section{References}

1. Amarante P. Loucos pela vida: a trajetória da reforma psiquiátrica no Brasil. Rio de Janeiro: Fiocruz; 2013.

2. Ministério da Saúde (BR). Secretaria Executiva. Legislação em saúde mental: 1990-2004. 5. Brasília; Ministério da Saúde; 2004.

3. Ministério da Saúde (BR). 2 a Conferência Nacional de Saúde Mental. Brasília: Ministério da Saúde; 1992.

4. Bardin L. Análise de conteúdo. Lisboa, Portugal: Edições 70; 2011.

5. Salles MM, Barros S. The social exclusion/inclusion of users of a psychosocial care center in everyday life. Texto Contexto Enferm. 2013; 22(3):704-12. 
6. Hansson L, Stjernswärd S, Svensson B. Perceived and anticipated discrimination in people with mental illness--an interview study. Nord J Psychiatry. 2014; 68(2):100-6.

7. Tavares CMM, Cortez EA, Muniz MP. Care in psychiatric hospital under the perspective of a nursing team. Rev Rene. 2014; 15(2):282-90.

8. Silva NG, Silva PP, Oliveira AGB. A percepção dos trabalhadores de enfermagem sobre a assistência à saúde mental em hospital universitário. Cienc Cuid Saude. 2012; 11(2):302-10.

9. Paes MR, Maftum MA. Dificuldades da equipe de enfermagem de um hospital geral no cuidado ao paciente com transtorno mental. Rev enferm UFPE on line. [periódico na Internet]. 2013 [citado 2016 jan 25]; 7(9):5566-73. Disponível em: file:///C:/ Users/User/Downloads/3756-46176-1-PB\%20 (1).pdf

10. Ortega LB, Ventura CA. I am alone: the experience of nurses delivering care to alcohol and drug users. Rev Esc Enferm USP. 2013; 47(6):1381-8.
11. Sousa PF, Ribeiro LCM, Melo JRF, Maciel SC, Oliveira MX. Dependentes químicos em tratamento: um estudo sobre a motivação para mudança. Temas Psicol. 2013; 21(1):259-68.

12. Cardoso LRD, Malbergier A. Problemas escolares e o consumo de álcool e outras drogas entre adolescentes. Psicol Esc Educ. 2014; 18(1):27-34.

13. Silva NS, Esperidião E, Cavalcante ACG, Souza ACS, Silva KKC. Development of human resources for work in mental health services. Texto Contexto Enferm. 2013; 22(4):1142-51.

14. Stahlschmidt APM. Integralidade, construção e socialização de conhecimentos no contexto da educação permanente e atuação de profissionais da área da saúde. Interface (Botucatu). 2012; 16(42):819-27.

15. Pinho LB, Kantorski LP, Olschowsky A, Schneider JF, Lacchini AJB. Ideology and mental health: analysis of the discourse of workers in the psychosocial area. Texto Contexto Enferm. 2014; 23(1):65-73. 